\title{
A CAMADA DE MISTURA NA REGIÃO DA PISCINA DE ÁGUAS QUENTES DO ATLÂNTICO TROPICAL
}

\author{
Marcelo Sandin Dourado \\ Universidade Federal do Paraná - Centro de Estudos do Mar \\ dourado@ufpr.br
}

\section{RESUMO}

A camada de mistura da Piscina de Águas Quentes do Atlântico Tropical é investigada utilizando um modelo unidimensional. Os resultados mostram que a salinidade pode ser importante na manutenção da piscina e a advecção no seu desaparecimento.

Palavras-chave: Temperatura da água do Mar, Camada de Mistura, Piscina de águas quentes do Atlântico.

\begin{abstract}
The mixed layer of the Tropical Atlantic warm pool is investigated using a one-dimensional model. The results show that the salinity may be important in the maintenance of the pool and the advection the responsible for its disappearance.
\end{abstract}

Key words: Sea Temperature, Mixing Layer, Tropical Atlantic Warm Pool.

\section{INTRODUÇÃO}

A piscina de águas quentes do Atlântico tropical (Fig. 1) contribui para modular a variabilidade da TSM sobre a bacia do Atlântico Tropical e favorece a formação do ramo sul da Zona de Convergência Intertropical. A formação deste ramo tem consequências importantes na modulação da variabilidade interanual da estação chuvosa sobre o nordeste brasileiro. Neste artigo, a camada de mistura da Piscina de Águas Quentes do Atlântico Tropical é investigada utilizando um modelo unidimensional proposto por Gaspar et al., 
1990. Os dados utilizados para inicializar, forçar e validar o modelo provem da bóia PIRATA localizada em $8^{\circ} \mathrm{S} 34^{\circ} \mathrm{W}$.

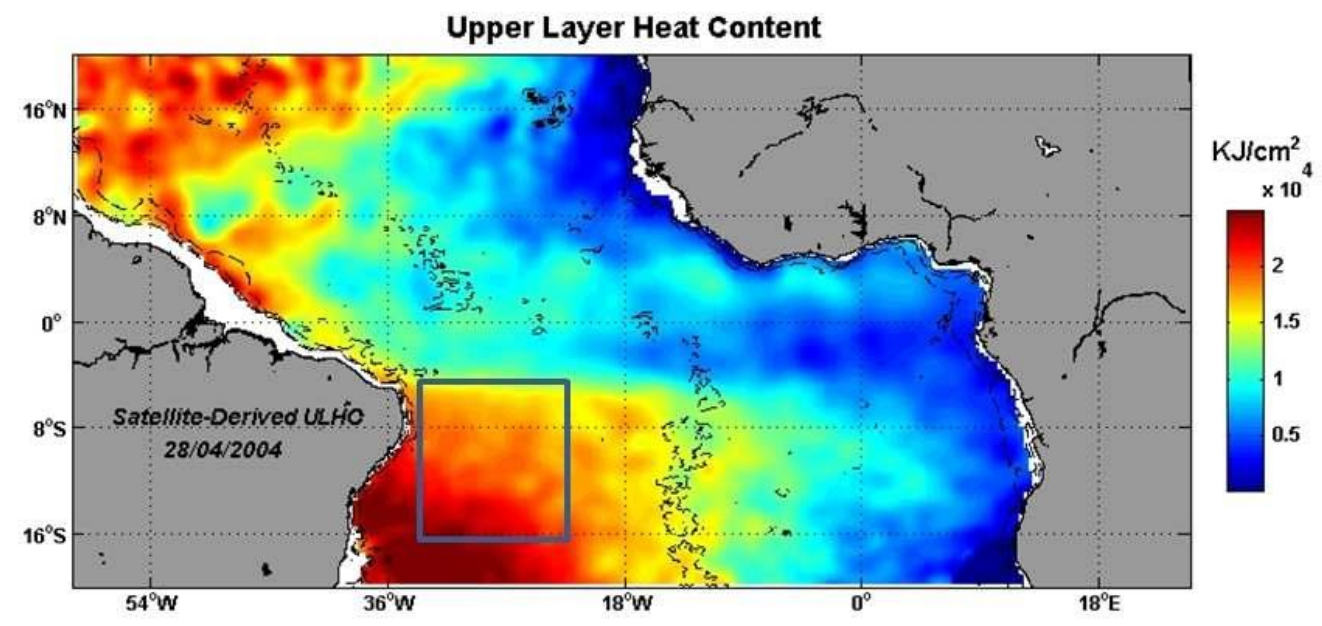

Figura 1: quantidade de calor calculada para a região do Atlântico tropical derivado de dados climatológicos e de satélite (x $104 \mathrm{KJ} / \mathrm{cm} 2)$ para o dia 28 de abril de 2004 (Lentini et al., 2006).

\section{RESULTADOS E DISCUSSÃO}

A figura 2 mostra a evolução da temperatura do mar modelada e observada para o período de 1 de abril (dia juliano 90) a 30 de maio (150) de 2006. De uma maneira geral, o modelo reproduz a variabilidade diurna observada. A amplitude diária média modelada (observada) é $0,28^{\circ} \mathrm{C}\left(0,29^{\circ} \mathrm{C}\right)$. Em particular, a correlação entre a temperatura modelada e observada é de 0,92 e o erro médio é de 0,078 . Os valores médios (desvio padrão) são 29,05 $(0,17)$ e 29,04 $(0,2)$ para a temperatura modelada e observada respectivamente. No entanto, o modelo subestima o máximo de temperatura no dia 29 de abril (dia juliano 119) e no final da simulação. A profundidade da camada de mistura estimada com um critério de densidade, com um valor médio de 49m., apresenta um ciclo diurno típico. Abruptas reduções na profundidade estão associadas a eventos de precipitação o que parece indicar que uma barreira de sal pode ser importante na manutenção da piscina de águas quentes. 

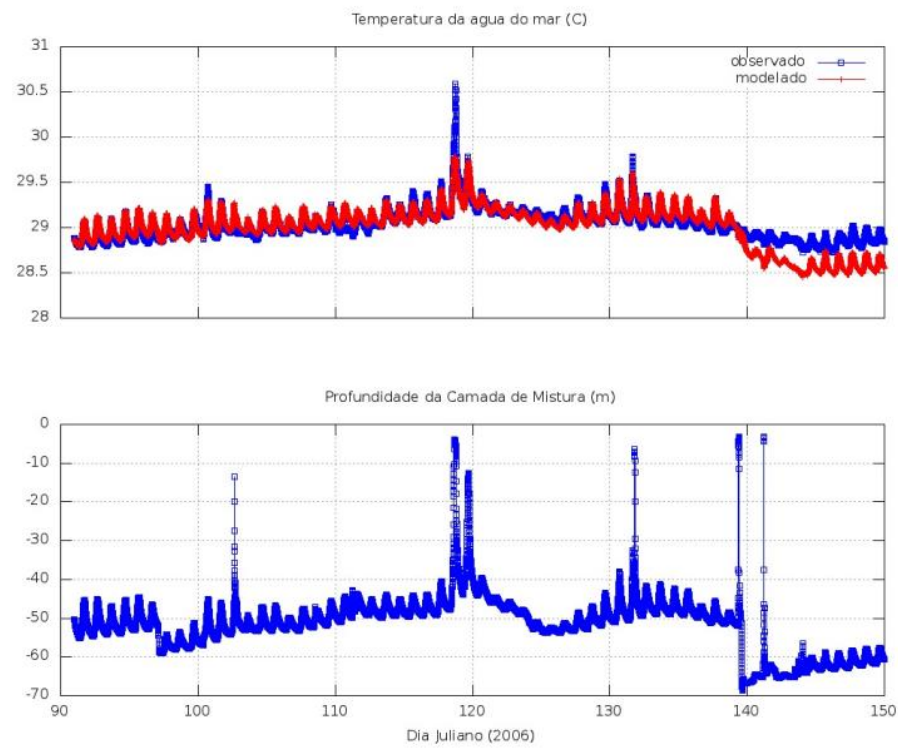

Figura 2: Acima: Temperatura da água do mar observada (azul) e modelada (vermelha). Abaixo: profundidade camada de mistura.

Os fluxos de calor latente, infravermelho líquido e sensível para o período de simulação são mostrados na figura 3 . Os valores médio são de $-128 \mathrm{~W} / \mathrm{m}^{2},-58 \mathrm{~W} / \mathrm{m}^{2}$ e -6 $\mathrm{W} / \mathrm{m}^{2}$ para o calor latente, infravermelho líquido e sensível respectivamente (valores negativos indicando fluxos para a atmosfera). Os fluxos mais intensos no final estão associados a um aumento na intensidade do vento (não mostrada). Isto também pode explicar as diferenças entre as temperaturas observadas e modeladas. A fraca intensidade do vento, por volta do dia juliano 119, controla o máximo de variabilidade diurna da temperatura observada $\left(1,5^{\circ} \mathrm{C}\right)$, e parece preponderante, quando comparado ao efeito da temperatura, no controle dos fluxos neste período.

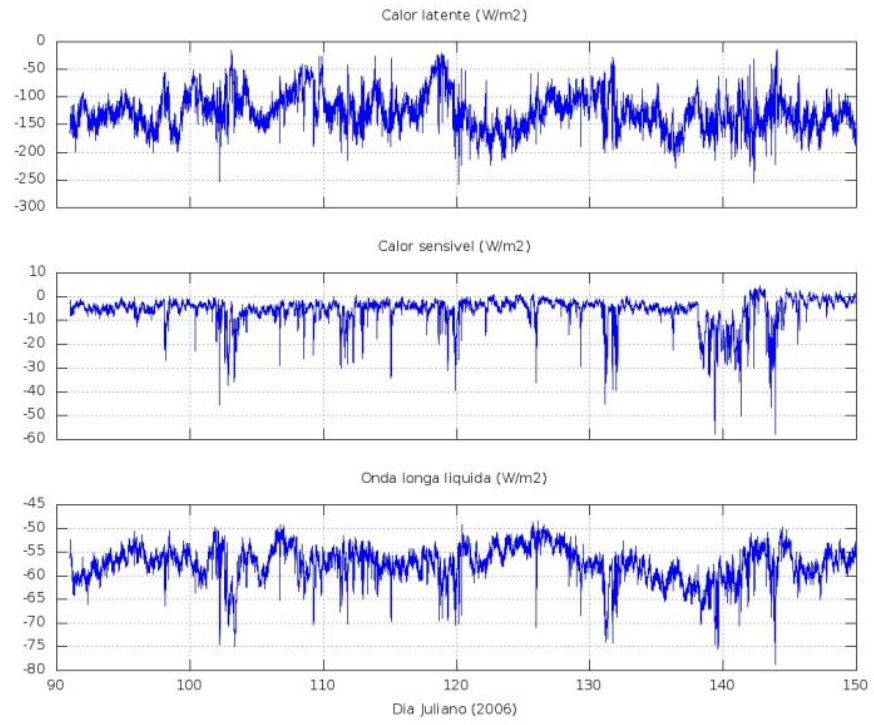

Figura 3: Fluxos de calor latente sensível e onda longa liquida para o período de simulação. 


\section{CONCLUSÃO}

O modelo reproduz bem a variabilidade diurna da temperatura da água do mar na região da piscina de águas quentes, com exceção do final da simulação. Isto parece associado ao aumento da velocidade do vento e pode indicar que o termo da advecção é importante para o desaparecimento da piscina de águas quentes a partir de maio. A profundidade da camada de mistura acompanha a variabilidade diurna, mas reduções significativas e pontuais, associados aos eventos de chuva indicam que a salinidade pode ser importante para a manutenção da piscina de águas quentes.

\section{REFERÊNCIAS BIBLIOGRÁFICAS}

Gaspar, P., Y. Grégoris, and J-M. Levèvre, A simple eddy kinetic energy model for simulations of the oceanic mixing: tests at station Papa and long-term upper ocean study site. J. Geophys. Res., 95, 16179-16193, 1990. 